\title{
Arquiteturas pedagógicas no processo de empreender: do fazer ao compreender no contexto da educação a distância
}

\section{Pedagogical architecture in the process of entrepreneur: do and understand in the context of distance education}

\author{
Ana Beatriz Michels \\ Universidade Federal do Rio Grande do Sul, UFRGS (Brasil) \\ Rosane Aragón \\ Universidade Federal do Rio Grande do Sul, UFRGS (Brasil)
}

\section{Resumo}

O presente artigo tem como foco a análise do processo de construção de conhecimento sobre planejamento de negócios dos alunos-empreendedores do curso de extensão XIV Maratona de Empreendedorismo da UFRGS, a partir de suas vivências em duas arquiteturas pedagógicas adaptadas e utilizadas no curso: (i) Debate de Teses e (ii) Desafio-Problema: de empreendedor para empreendedor. Trata-se de uma pesquisa qualitativa, com fundamentação teórica nos pressupostos piagetianos da tomada de consciência e fazer e compreender. A pesquisa foi realizada com dez sujeitos e os dados foram coletados a partir do levantamento dos registros dos alunos nas arquiteturas pedagógicas Debate de Teses e Desafio-Problema, questionário online e entrevista final. Para a análise dos dados foram definidas duas categorias, com quatro níveis cada, que envolveram as compreensões conceituais do planejamento de negócios a partir do uso das arquiteturas pedagógicas. Os resultados do estudo apontaram que os sujeitos construíram conhecimento acerca do planejamento de negócios, alcançando uma compreensão contextualizada sobre o tema e, em alguns casos, uma compreensão antecipada, oportunizando a visualização de ações futuras para a implantação de ideias de negócio. Nesse processo de construção de conhecimento, as arquiteturas pedagógicas serviram de suporte para que o conhecimento fosse reconstruído durante toda a trajetória dos sujeitos no curso até atingirem um saber fazer conceituado.

Palavras-chave: arquitetura pedagógica; educação a distância; educação empreendedora; tomada de consciência; fazer e compreender.

\begin{abstract}
This article focuses on the analysis of the process of building knowledge about business planning of the student entrepreneurs of extension course XIV Marathon Entrepreneurship UFRGS, from his experiences in two adapted pedagogical architectures used in the course: (i)
\end{abstract}


Debate Theses and (ii) Challenge-Problem: entrepreneur to entrepreneur. It is a qualitative research, with theoretical basis in Piagetian assumptions of awareness and do and understand. The survey was conducted with ten subjects and data were collected from the survey of the records of students in pedagogical architectures Debate Theses and Challenge-Problem, online questionnaire and final interview. For the data analysis were defined two categories, with four each levels, involving the conceptual understanding of business planning from the use of pedagogical architectures. The study results showed that the subjects built knowledge about business planning, reaching a contextualized understanding of the topic and, in some cases, an early understanding, providing opportunities to display future actions for the implementation of business ideas. In the process of building knowledge, pedagogical architectures served as a support for knowledge were rebuilt during the entire trajectory of the subjects in the course, until they reach a reputable know-how.

Keywords: pedagogical architecture; distance education; entrepreneurial education; awareness; do and understand.

Pessoas empreendedoras utilizam a sua criatividade para transformar o seu entorno, gerando inovação e provocando mudanças no cenário em que estão inseridas (Guerra, Graziottin in Lopes, 2010). Algumas das características de pessoas empreendedoras - autonomia, criatividade, trabalho em equipe, tomada de decisões, aprendizagem a partir dos erros, etc. (Neck, Greene e Brush, 2014) são competências exigidas pela sociedade contemporânea. Para desenvolver essas competências, precisamos também desenvolver uma educação em uma perspectiva empreendedora, buscando caminhos para a reestruturação e renovação dos projetos pedagógicos.

A educação empreendedora, aliada às tecnologias digitais como suporte a processos de interação e cooperação, instaura um ambiente de ensino e aprendizagem favorável ao desenvolvimento do pensamento criativo e à produção de novidades, já que os estudantes tem oportunidade de debater ideias a partir de situações reais, analisar experiências e realizar projetos.

Segundo Moore e Kearsley (2007, p. 265), as estratégias de ensino devem, "[...] aproveitar plenamente a natureza interativa da tecnologia que estiver sendo utilizada”. Dessa forma, é necessário fazer com que os alunos participem ativamente nas atividades propostas, incentivando-os a levantarem questionamentos, a realizarem apresentações, a interagirem com os demais colegas, em suma, envolvendo-os plenamente nos processos de ensino e aprendizagem (Moore e Kearsley, 2007). Nessa transformação, os alunos ultrapassam a barreira da mera cópia da realidade, podendo inovar nas suas áreas de conhecimento, adotando a opção de serem proativos e protagonistas de suas vidas.

A UFRGS tem disseminado a cultura empreendedora e, desde 2000, a Secretaria de Desenvolvimento Tecnológico (SEDETEC) ${ }^{1}$ realiza a Maratona de Empreendedorismo ${ }^{2}$, que tem como objetivo desenvolver o potencial dos 
empreendedores, em destaque os da região metropolitana do Estado do Rio Grande do Sul, capacitando no planejamento de seus negócios inovadores e possibilitando que os participantes testem suas ideias e as coloquem em prática. As atividades desenvolvidas no curso focam na construção de conhecimento dos alunos-empreendedores, buscando que esses tomem consciência e transfiram seus aprendizados para situações semelhantes.

O presente artigo apresenta uma síntese de uma pesquisa de Mestrado acerca do processo de construção de conhecimento sobre planejamento de negócios dos alunos-empreendedores do curso de extensão XIV Maratona de Empreendedorismo da UFRGS. O curso foi realizado no segundo semestre de 2013, abrangendo atividades presenciais e a distância, com o suporte do ambiente virtual de aprendizagem Moodle.

Considerando a abordagem construtivista adotada nesta pesquisa, foram adaptadas duas arquiteturas pedagógicas com foco na construção de conhecimento dos alunos, denominadas "Debate de Teses" e "Desafio-problema". Nesse contexto, definimos Arquiteturas Pedagógicas como "suportes estruturantes" para a aprendizagem que combinam visão epistemológica, concepção pedagógica e recursos tecnológicos, dentro de uma visão ecossistêmica (Nevado, Dalpiaz e Menezes, 2009).

Este estudo visa analisar o processo de construção de conhecimento dos alunosempreendedores do curso XIV Maratona de Empreendedorismo da UFRGS, a partir de suas vivências/experiências nas arquiteturas pedagógicas de debate de teses e de resolução de problemas.

\section{CONSTRUÇÃO DE CONHECIMENTO: O "SABER FAZER" E O COMPREENDER}

A partir de um modelo interacionista (Piaget, 2007), a construção de conhecimento ocorre de forma contínua e resulta da interação entre o sujeito e o meio. Nessa interação, o desenvolvimento do conhecimento ocorre na medida em que o sujeito interage com os objetos, a partir de suas ações, sejam elas práticas ou mentais. O sujeito "[...] só aprenderá alguma coisa, isto é, construirá algum conhecimento novo, se ele agir e problematizar a própria ação, apropriar-se dela e de seus mecanismos íntimos” (Becker, 2012, p. 21).

Nesse modelo, o sujeito é um ser ativo, protagonista de suas aprendizagens. Mas como o sujeito, na sua interação com o objeto, constrói conhecimento? Para construir conhecimento, o sujeito, ao agir sobre o objeto, precisa sentir necessidade, ser desafiado, precisa estar em desequilíbrio cognitivo. Um desequilíbrio é a expressão de uma lacuna, uma necessidade que corresponde a um objetivo do comportamento humano. Nessa concepção, "[...] conhecer consiste em agir sobre o real e em transformá-lo, incorporando-o aos esquemas ${ }^{3}$ do sujeito" (Montangero e Maurice-Naville, 1998, p. 169). 
Nesse processo construtivo, o sujeito inicialmente toma consciência do resultado da sua ação para, posteriormente, tomar consciência do seu processo. Para alcançar a compreensão de um processo, o sujeito precisa passar pelo sucesso prático (saber fazer), para, a partir de certo nível, alcançar melhores níveis de compreensão, possibilitando que o sujeito coordene suas ações e as reconstrua.

O sujeito tomará consciência de suas ações no momento que reconstruir suas concepções/ideias/ações anteriores. Ele passa a compreender a realização de uma atividade ou tarefa bem como o percurso realizado para tal e os efeitos produzidos durante o processo. Com isso, o sujeito passa a formular hipóteses e fazer experimentações e efetuar novas operações que resultarão na produção de novas formas de fazer, de compreender e de empreender.

Nesse sentido, o conseguir - ou o sucesso - em uma ação, em um planejamento, etc., pode ser inicialmente o resultado de um "saber fazer". Porém, só no nível da ação conceituada é que o sujeito terá consciência das razões ou motivos que o levaram a uma ação exitosa ou ao alcance dos seus objetivos.

\section{ARQUITETURAS PEDAGÓGICAS PARA A EAD}

A EAD não se constitui em uma modalidade inovadora pelo simples fato de utilizar as tecnologias digitais nos processos de ensino e aprendizagem. Existem modelos diferenciados de $\mathrm{EAD}$ e o que se percebe em sua grande maioria é uma ênfase nos processos de ensino, e não nos processos de aprendizagem (Belloni, 2008).

O fato das instituições de ensino utilizarem as tecnologias digitais para melhorar a eficiência do seu sistema de ensino a distância não significa que estão, necessariamente, inovando nos seus processos educacionais, pois a tecnologia por si só não representa uma prática construtiva e nem possibilita que os alunos tenham uma aprendizagem ativa.

As tecnologias digitais oferecem diversas possibilidades para potencializar as práticas educacionais favorecendo as interações e a criação de comunidades de aprendizagem, contribuindo para que os alunos interajam e, consequentemente, construam o conhecimento. Nessa construção de conhecimento, o aluno precisa ser provocado por situações de desequilíbrio e, a partir de seus conhecimentos prévios, faz progressivas reconstruções.

Para apoiar essas reconstruções, tanto os professores quanto as tecnologias digitais precisam dar suporte aos alunos. Nessa perspectiva é proposta a ideia de arquiteturas pedagógicas, que são "[...] estruturas de aprendizagem realizadas a partir da confluência de diferentes componentes: abordagem pedagógica, software educacional, internet, EAD, concepção de tempo e de espaço" (Nevado, Carvalho e Menezes, 2007, p. 39).

Na proposta das arquiteturas pedagógicas, a aprendizagem é vista como um processo de ação e reflexão sobre a ação, sendo construída a partir da vivência 
dos alunos. Dessa forma, as arquiteturas pedagógicas não se confundem com atividades normalmente propostas em sala de aula, voltadas para a transmissão de informações, o uso excessivo de exercícios repetitivos, em que os professores tentam educar seus alunos a partir da imposição de atividades. Ao invés de se apoiar numa pedagogia diretiva, embasada no modelo empirista de ensino, o uso de arquiteturas pedagógicas em sala de aula pressupõe uma pedagogia relacional, em que o professor desenvolve atividades vinculadas à realidade dos seus alunos. Nesse contexto, as atividades buscam a interação e intervenções problematizadoras, atuando "[...] de forma a provocar, por um lado, desequilíbrios cognitivos e, por outro, suportes para as reconstruções. Dessa forma, as arquiteturas solicitam do estudante atitudes ativas e reflexivas a partir de estruturas de trabalho interativas e construtivas" (Nevado, Dalpiaz e Menezes, 2009).

O uso de arquiteturas pedagógicas em sala de aula, além da união de diferentes ferramentas, contempla a intenção pedagógica do que se deseja com o uso dessas ferramentas. Assim, as ferramentas são usadas para qualificar o processo de aprendizagem que não está assentado nas certezas, e sim na dúvida, na incerteza, no debate, na troca, nas interações (Nevado, Carvalho e Menezes, 2007).

As arquiteturas pedagógicas não envolvem apenas práticas criativas com o uso das tecnologias digitais, mas também uma teoria explicitada e uma sistematização da metodologia (Nevado, Carvalho e Menezes, 2007). A confluência desses elementos possibilita que as arquiteturas pedagógicas sejam desenvolvidas de forma mais flexível e adaptável a diferentes contextos, sendo uma grande aliada dos professores em sala de aula.

Como exemplos, apresentamos a seguir as arquiteturas pedagógicas que foram aplicadas no estudo. As dinâmicas das arquiteturas serão descritas no percurso metodológico do estudo.

\section{Arquitetura Pedagógica "Desafio -Problema"}

No aprendizado baseado em problemas, o aluno é desafiado a buscar soluções para problemas reais a partir dos seus conhecimentos prévios, através de sua capacidade cognitiva que é, fundamentalmente, a capacidade de inferência. De acordo com Becker (1999, p. 76), essa capacidade faz com que o aluno passe de um "conhecimento qualquer a outro; de um conhecimento mais simples a um mais complexo; de uma ação prática que busca êxito a uma pergunta que mira a verdade, a explicação, a razão, a compreensão, o porquê".

O uso de algum caso ou problema só tem sentido para os alunos se eles tiverem interesse em saber sobre isto. $\mathrm{E}$ a necessidade em analisar um caso ou problema não se põe a priori, deve ser criada pelos próprios alunos ou pela situação em que é apresentada (Nevado, Carvalho e Menezes, 2007).

A arquitetura pedagógica de resolução de problemas precisa dar condições para que as reconstruções ocorram de forma sistemática através de um suporte telemático 
apoiado em três componentes de software: (1) ambiente de autoria de casos; (2) ambiente de resolução de casos; (3) ambiente para apoio de recuperação de casos (Nevado, Carvalho e Menezes, 2007).

\section{Arquitetura Pedagógica "Debate de Teses"}

O que se pretende promover com essa arquitetura é que indivíduos em processo de compreensão de um determinado "micromundo" elaborem seus conhecimentos apoiados por uma rede de interações. O ponto de partida é a compreensão dos sujeitos sobre conceitos envolvidos no micromundo considerado. A partir do momento em que cada sujeito revela sua compreensão acerca de determinado conceito, é possível estabelecer um debate coletivo identificando semelhanças e diferenças entre as suas concepções.

O ponto culminante do processo é a reelaboração, ou seja, o processo coletivo de construção/reconstrução conceitual que os sujeitos realizam nas suas interações interindividuais e nas suas interações com diferentes fontes de informação (documentos, experimentos, fatos, simulações), modificando os significados do micromundo em questão (Nevado, Dalpiaz e Menezes, 2009).

\section{EDUCAÇÃO EMPREENDEDORA A DISTÂNCIA}

Empreender é um processo essencialmente humano e o empreendedor é visto como aquele que inova, propondo maneiras diferentes de fazer as coisas. Relacionando com as obras de Piaget, ele sempre afirmou que o conhecimento não é imitação, uma mera cópia da realidade, e sim uma estruturação da realidade, um enriquecimento (Piaget, 2001).

$\mathrm{O}$ ato de empreender como construção do futuro ocasionou a inserção de propostas com uma finalidade educacional, estabelecendo-se uma educação empreendedora. Ela é caracterizada pela construção de conhecimentos novos a partir de conhecimentos precedentes e visa capacitar os estudantes para serem pessoas ativas (Lavieri in Lopes, 2010).

A natureza da educação empreendedora está mudando e hoje ela não está centrada apenas no currículo de um curso específico, pois está sendo vista como um método composto por um portfólio de práticas. E essas práticas podem ser utilizadas em qualquer curso (Neck, Greene e Brush, 2014).

Com as mudanças no cenário econômico e o avanço das tecnologias, a sociedade vem exigindo pessoas mais qualificadas, que pensem de forma holística, que sejam flexíveis, que estejam abertas às mudanças. Isso requer do sistema de ensino o desenvolvimento de novas competências exigidas na sociedade da informação, do conhecimento, ou na sociedade em rede. As mudanças advindas da sociedade em rede criam um novo espaço pedagógico que busca o desenvolvimento das competências 
do indivíduo, respeitando o ritmo de cada um, e a formação de comunidades de aprendizagem (Behar, 2009).

Tanto as grandes empresas quanto o governo têm aumentado seus investimentos em tecnologias digitais com o intuito de melhorar as redes de comunicação e o acesso à internet por parte dos cidadãos, como afirma Coll e Monereo (2010, p. 17), "pensando principalmente nos desafios do comércio (e-business), do trabalho (e-work), da governabilidade (e-governance) e da educação (e-learning) a distância" (Coll e Monereo, 2010, p. 22).

Há alguns anos, atividades empreendedoras na modalidade de EAD têm promovido a aprendizagem ativa - que combina o trabalho individual e o trabalho em equipes, levando a uma educação da autodisciplina e do esforço voluntário (Piaget, 2010). Os métodos mais utilizados são as simulações de negócios, os jogos de negócios, cursos online e MOOC - Massive Open Online Course.

\section{PERCURSO METODOLÓGICO}

Esta pesquisa propôs um estudo de caso de natureza qualitativa e analisou como ocorreu o processo de compreensão do planejamento de negócios dos alunosempreendedores do curso de extensão XIV Maratona de Empreendedorismo do UFRGS, a partir de duas arquiteturas pedagógicas adaptadas para o curso: Debate de Teses e Desafio-Problema: de empreendedor para empreendedor. Essa opção metodológica deve-se ao fato de que a pesquisa qualitativa está interessada nas perspectivas dos participantes, em suas práticas e conhecimento cotidiano relativo à questão em estudo (Flick, 2011).

Os sujeitos da pesquisa foram dez alunos-empreendedores do curso de extensão XIV Maratona de Empreendedorismo do UFRGS, que é um curso presencial e a distância voltado para a criação de negócios. O curso foi realizado nos meses de julho a outubro de 2013, sendo capacitadas 74 pessoas. A amostra dos dez sujeitos para a pesquisa foi escolhida de forma intencional, levando-se em consideração os seguintes critérios: (i) ter participado das atividades realizadas nas duas arquiteturas pedagógicas que foram desenvolvidas no projeto e (ii) ter finalizado o curso, ou seja, ter entregue o plano de negócios ${ }^{4}$.

Nesta pesquisa foram adaptadas as duas arquiteturas pedagógicas apresentadas anteriormente, tendo como contexto a educação empreendedora. Elas foram desenvolvidas para o curso de extensão XIV Maratona de Empreendedorismo do UFRGS com o intuito de propiciar um espaço de construção de conhecimento para os alunos-empreendedores através da reconstrução de suas certezas provisórias relacionadas ao planejamento de negócios.

$\mathrm{Na}$ arquitetura pedagógica Debate de $\mathrm{Teses}^{5}$, as teses - afirmações sobre o planejamento de negócios - foram escolhidas a partir de um questionário online respondido pelos alunos que foram selecionados para o curso. A atividade foi realizada em quatro etapas, sendo que duas ocorreram antes do início das aulas presencias da 
XIV Maratona de Empreendedorismo do UFRGS. Para começar a atividade, cada participante do curso foi cadastrado no ambiente e recebeu por e-mail um tutorial para uso do mesmo. Dessa forma foi criada uma página de debate para cada aluno para que ele tivesse acesso a todas as etapas da atividade, sendo elas:

I. posicionamento inicial, etapa em que os alunos informaram se concordaram ou não com as teses e argumentaram seus posicionamentos. Nessa etapa, a ideia principal era que os alunos inserissem suas "certezas provisórias" sobre as teses, mesmo tendo pouco ou nenhum conhecimento acerca das mesmas. A sugestão foi que argumentassem com suas palavras. Além disso, os alunos poderiam inserir algum exemplo de casos de empreendedores que justificasse $o$ seu posicionamento;

II. revisão da argumentação de outros dois colegas, questionando-os acerca das suas afirmações. $\mathrm{O}$ revisor poderia concordar ou não com o posicionamento dos colegas. Para a organização dos revisores, os alunos foram divididos em três grupos em relação ao nível de conhecimento acerca do planejamento de negócios, que foram definidos a partir do questionário online realizado antes do início da atividade. Os revisores para a página de cada aluno foram escolhidos de acordo com os grupos, buscando escolher um revisor do mesmo grupo e o outro de um grupo diferente;

III. contra-argumentação em relação aos feedbacks recebidos dos outros dois colegas. Cada aluno fez uma contra-argumentação em relação aos feedbacks recebidos dos outros dois colegas. Para auxiliar, essa etapa ocorreu paralelo às aulas da XIV Maratona de Empreendedorismo do UFRGS e os alunos puderam elaborar suas contra-argumentações a partir de suas aprendizagens no decorrer das aulas, tanto em relação às trocas com os professores e demais colegas quanto em relação ao material de apoio disponibilizado no ambiente Moodle;

IV. posicionamento final acerca das teses. A partir da construção cooperativa de conhecimento nas etapas anteriores, cada aluno se posicionou novamente em relação às teses. $\mathrm{O}$ fato da construção de conhecimento ter ocorrido em rede, cada aluno pode refletir sobre suas argumentações iniciais e, a partir do diálogo com outros quatro colegas, puderam reelaborar seus posicionamentos iniciais. Junto com o posicionamento final, o ambiente disponibilizou um espaço para que os alunos refletissem sobre a atividade e apontassem os pontos positivos e negativos do uso da arquitetura pedagógica no curso.

Os objetivos da atividade foram: (i) verificar os conhecimentos prévios dos alunos em relação aos temas abordados nas teses; (ii) possibilitar a construção de conhecimento acerca das teses; (iii) propiciar uma exploração individual e coletiva sobre as teses; (iv) oportunizar um espaço de reflexão e experimentação de estratégias de feedback e contra-argumentação, facilitando a elaboração do modelo de negócios e do plano de negócios. 
Já na arquitetura pedagógica "Desafio-Problema: de empreendedor para empreendedor", as situações-problema foram levantadas a partir de situações vivenciadas por ex-participantes do curso e que, atualmente, estão com suas empresas atuantes no mercado, permitindo uma aproximação a situações reais. Para o desenvolvimento da arquitetura, inicialmente foram gravados vídeos com essas empresas. Nesses vídeos, os empreendedores apresentaram um desafio/problema que vivenciaram em suas empresas, contextualizando a situação e finalizando o vídeo com uma questão desafio.

A atividade foi realizada no ambiente virtual de aprendizagem Moodle, em cinco etapas:

I. escolha do desafio pelos alunos. Na primeira etapa da atividade, foram apresentados os vídeos com os desafios-problema e cada aluno escolheu o vídeo que pretendia trabalhar. Os vídeos foram inseridos no Moodle e, através do recurso Escolha, cada aluno optou por um deles. Nesse momento, os estudantes podiam visualizar a escolha dos colegas e, ao término, foram agrupados em equipes de, no máximo, seis participantes, levando em consideração suas escolhas;

II. posicionamento individual dos alunos acerca do desafio e proposta de solução a partir de seus conhecimentos prévios registrados no diário de bordo do ambiente Moodle;

III. levantamento em grupo das possíveis soluções. Após o posicionamento individual, os grupos passaram a fase de debate das soluções levantadas, com o auxílio da atividade Fórum;

IV. apresentação presencial das soluções do desafio;

V. reavaliação individual das soluções.

A busca por possíveis soluções aos problemas foi realizada de forma cooperativa, a partir da confluência de: (a) experiências já vivenciadas pelos alunos ou por outros sujeitos; (b) experiências que estão sendo vivenciadas pelos alunos ou por outros sujeitos; (c) informações disponibilizadas no ambiente de aprendizagem, tanto pelos professores quanto pelos alunos, como textos, vídeos, links, etc.; ou (d) experiências que poderão ser vivenciadas pelos alunos ou por outros sujeitos.

A arquitetura pedagógica foi desenvolvida com vista a: (i) ampliar o portfólio de atividades da XIV Maratona de Empreendedorismo do UFRGS; (ii) proporcionar aos alunos-empreendedores experiências significativas com desafios reais de empresas, incentivando-os a agir criticamente e refletir sobre estes desafios; (iii) estimular a interação e cooperação entre os aprendizes, mediante a proposta de trabalho em equipe; (iv) contribuir para o desenvolvimento do potencial empreendedor dos participantes; $(v)$ propiciar aos ex-maratonistas um espaço de busca de soluções 
inovadoras e criativas para os problemas vivenciados por suas empresas, através do debate com os demais participantes.

Por se tratar de um estudo de caso de natureza qualitativa, em que o pesquisador se preocupa mais com o processo do que com o produto (Ludke e André, 1986), nesta pesquisa foram utilizados os instrumentos de questionário online, relatos e discussões dos sujeitos registrados nos ambientes das arquiteturas pedagógicas e entrevista final. Os dados coletados foram levantados em três momentos: (1) período pré-curso; (2) período de realização do curso e (3) período pós-curso.

Num primeiro momento foram organizados os dados dos questionários online e foi feita a leitura de alguns relatos inseridos nas arquiteturas pedagógicas de debate de teses e de resolução de problemas. O software NVivo foi utilizado para organizar os dados coletados de cada sujeito e relacioná-los com as categorias, pois ele "[...] trabalha com o conceito de projeto. As fontes de informação do projeto, assim como os dados gerados durante o processo de análise, como categorias de informações, são armazenadas em um banco de dados" (Bringer, Johnson, Bracknridge apud Lage, 2011, p. 203).

\section{ANÁLISE E DISCUSSÃo DOS DADOS}

Neste estudo foram consideradas duas categorias que focaram na compreensão conceitual dos sujeitos sobre o planejamento de negócios, a partir do uso das arquiteturas pedagógicas Debate de Teses e Desafio-Problema: de empreendedor para empreendedor. Cada categoria apresentou quatro níveis: (I) compreensão inicial, em que o aluno-empreendedor tem ideias iniciais acerca do planejamento de negócios; (II) compreensão conceitual parcial, em que o aluno-empreendedor apresenta uma conceituação parcial dos conceitos envolvidos no planejamento de negócios, relacionando-os com a definição teórica; (III) compreensão contextualizada, em que o aluno-empreendedor compreende os conceitos envolvidos no planejamento de negócios, sendo que essa conceituação se dá no contexto do curso, principalmente pelo seu uso no processo de planejamento do seu negócio; (IV) compreensão antecipada, em que a compreensão dos conceitos envolvidos no planejamento de negócios faz com que o aluno-empreendedor construa as possibilidades de generalização e antecipação, visualizando futuras melhoras e/ou alterações no seu projeto e em outras situações.

A análise e discussão dos dados foram estruturadas em dois tópicos: (I) análise geral da trajetória dos sujeitos do início ao término do curso em relação às duas categorias; (II) análise da avaliação dos sujeitos em relação às duas arquiteturas pedagógicas. 


\section{Análise geral da Categoria 1: Compreensões conceituais a partir do uso da arquitetura pedagógica Debate de Teses}

Para compreender o planejamento de negócios, é necessário que o alunoempreendedor conheça os fatores básicos que possibilitam a transformação de uma ideia de negócio em uma oportunidade de mercado. A XIV Maratona de Empreendedorismo do UFRGS oportunizou o conhecimento desses fatores básicos, através de uma articulação teoria-prática, na qual o aluno-empreendedor modelou, a partir de um esboço inicial, a sua ideia de negócio a partir das necessidades do mercado.

O gráfico 1 exibe a evolução dos sujeitos, do início ao término do curso, em relação à categoria 1. Dentre os dez sujeitos analisados, seis iniciaram o curso no nível 1, que corresponde a uma compreensão inicial acerca dos conceitos envolvidos no planejamento de negócio, em destaque às ferramentas modelo de negócios e plano de negócios. Os sujeitos apresentaram suas ideias iniciais, supondo uma definição para as ferramentas, que se constitui como um êxito inicial. Essas ideias iniciais são chamadas de conceituações de primeiro grau, pois levam ao êxito, sendo um êxito precoce em relação à compreensão das ferramentas.

Os outros quatro sujeitos já tinham uma compreensão conceitual parcial acerca das ferramentas no início do curso, pois já tinham estudado e/ou desenvolvido o modelo de negócios e o plano de negócios de suas ideias de negócio. Por já terem vivenciado situações relacionadas ao planejamento de negócios, mesmo que tenham sido situações primárias, eles partiram de um patamar mais elevado de conhecimento. Os sujeitos não estavam apenas interessados em alcançar um resultado, que no caso do curso era a definição das ferramentas, mas em compreender o processo para alcançar o resultado. Isso é visto principalmente na análise individual de dois sujeitos, que buscaram relacionar seus conhecimentos com referenciais teóricos, para que pudessem comparar visões distintas ou para confirmar suas conceituações acerca das ferramentas. Portanto, conforme afirma Piaget (1978), houve um progresso da conceituação inicial para a compreensão prática, em que o sujeito pode coordenar conceituações distintas, que no caso da XIV Maratona de Empreendedorismo do UFRGS são os conhecimentos prévios dos sujeitos com a definição teórica em relação às ferramentas modelo de negócios e plano de negócios. 
Gráfico 1. Evolução dos sujeitos em relação à Categoria 1

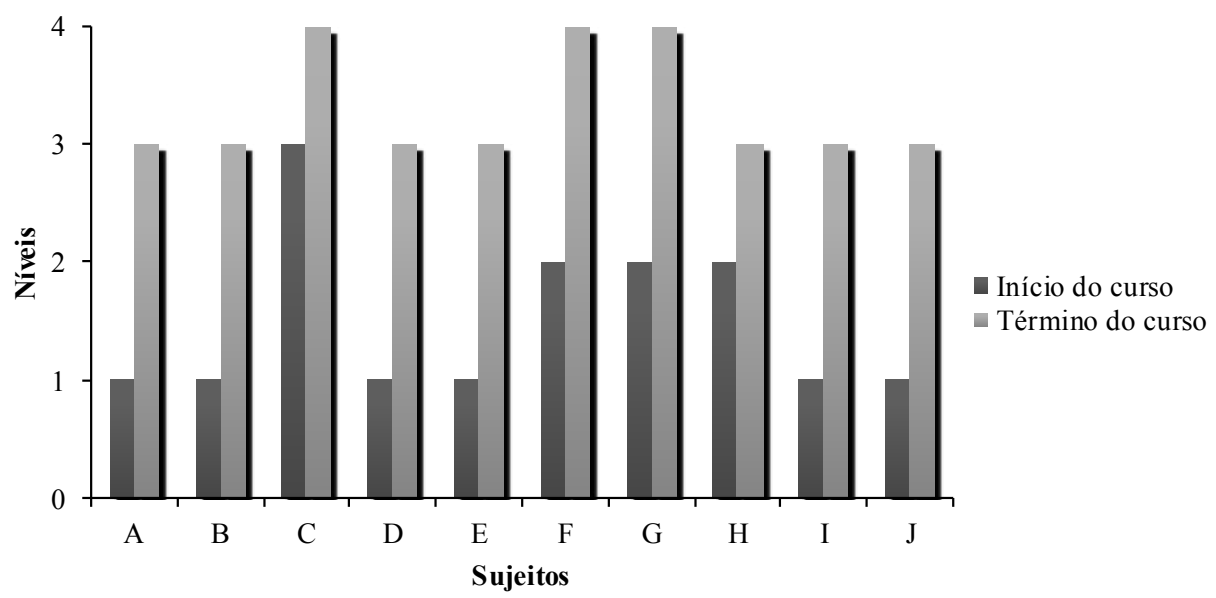

Analisando a evolução dos dez sujeitos, percebeu-se que os únicos sujeitos que alcançaram o nível 4, que corresponde a uma compreensão antecipada sobre o planejamento de negócios, foram os sujeitos que iniciaram o curso pelo menos no nível 2. Todos os outros sujeitos, que iniciaram o curso no nível 1, alcançaram no final do curso o nível 3, tendo uma compreensão contextualizada sobre o planejamento de negócios, pois desenvolveram durante o curso tanto o modelo de negócios quanto o plano de negócios de suas ideias.

Dessa forma, conclui-se que todos os sujeitos alcançaram, pelo menos, uma compreensão contextualizada das duas ferramentas, ou seja, eles compreenderam a conceituação de ambas as ferramentas e, a partir dessa conceituação, conseguiram desenvolver e/ou aprimorar o modelo de negócios e o plano de negócios dos seus projetos. Além de utilizar seus conhecimentos construídos no curso no desenvolvimento de seus projetos, três sujeitos alcançaram uma compreensão antecipada, ou seja, construíram possibilidades de generalização e antecipação, visualizando futuras melhoras e/ou alterações nos seus projetos. Isso corrobora o que Piaget (1978) conclui na sua obra Fazer e Compreender, no qual ele afirma que as ações de primeiro grau vão sendo coordenadas por ações mais complexas, que se tornam cada vez mais antecipadoras. 


\section{Análise geral da Categoria 2: Compreensões conceituais a partir do uso da arquitetura pedagógica Desafio-Problema: de empreendedor para empreendedor}

Para que o aluno-empreendedor tenha uma formação empreendedora, em destaque o planejamento do seu negócio, ele precisa ter uma visão holística, buscando conhecer o todo e a relação entre as partes que envolvem o planejamento de negócios (Souza, 2000, apud Souza et al, 2005). Como a maioria dos alunos-empreendedores não tinha empresa no período de participação no curso, para que eles pudessem conhecer o todo que envolve o planejamento de negócios, o contexto oportunizado pelo curso favoreceu a interação com problemas, situações e pessoas, que são pontos abordados por Lopes (2010).

O gráfico 2 exibe a evolução de cada sujeito, do início ao término do curso, em relação à categoria 2. Apenas quatro sujeitos iniciaram o curso no nível 1, sem uma compreensão parcial acerca do planejamento de negócios. No momento inicial de levantamento de ideias/soluções acerca dos desafios utilizados na arquitetura Desafio-Problema, esses sujeitos apresentaram ideias soltas, sem terem argumentos que fortalecessem seus pontos de vista. Essa compreensão inicial mostra que o sujeito se interessa essencialmente pelo resultado - que no caso do curso era apresentar soluções para o desafio - e acaba negligenciando o como (Piaget, 1978), ou seja, os argumentos que levaram o sujeito a construir determinadas ideias.

Gráfico 2. Evolução dos sujeitos em relação à Categoria 2

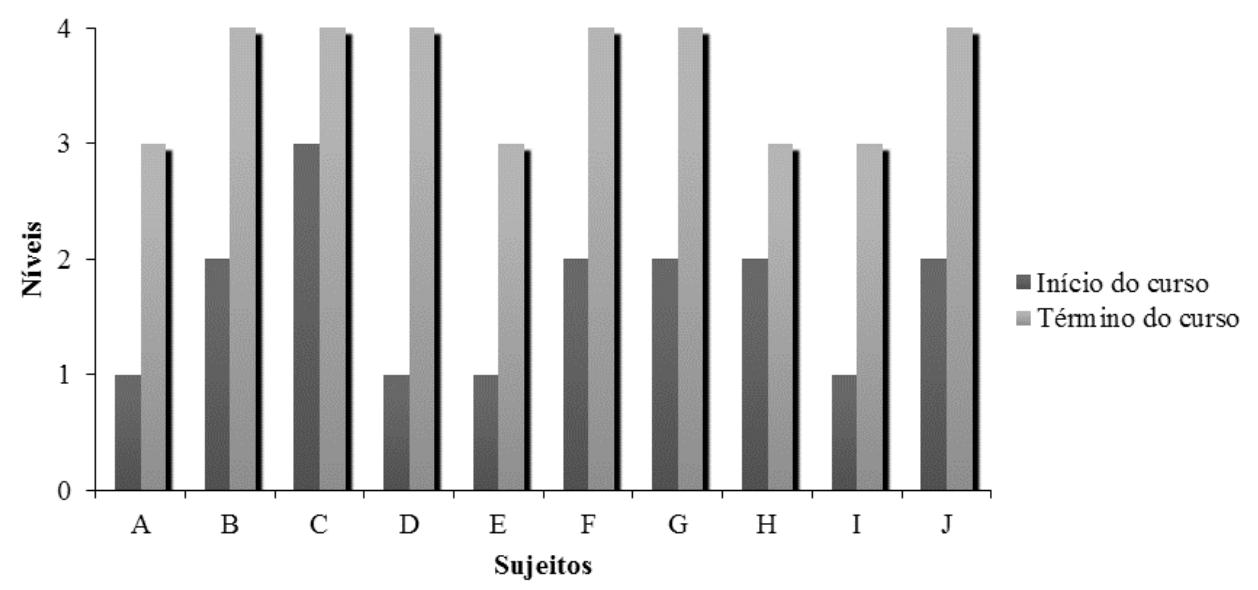

Os sujeitos que na categoria 1 iniciaram o curso no nível 2, também nesta categoria iniciaram no nível 2, com uma compreensão conceitual parcial. Como 
eles já tinham um conhecimento inicial acerca do planejamento de negócios, ou por terem participado de algum curso ou por já terem empresa, as ideias/soluções apresentadas na arquitetura pedagógica Desafio-Problema foram argumentadas e relacionadas, mostrando que, nesse nível de compreensão, a ação e sua conceituação são aproximadamente do mesmo nível e em que se efetuam trocas constantes entre as duas (Piaget, 1978).

Dentre os dez sujeitos do estudo, seis sujeitos alcançaram um patamar superior de conhecimento no término do curso, pois conseguiram prever soluções para problemas que poderão surgir no dia-a-dia do seu negócio. Mais da metade desses sujeitos passou por, pelo menos, três etapas de todo processo que inicia num fazer até alcançar o compreender, buscando um novo fazer conceituado. Alguns deles iniciaram com ideias soltas, experiências simples "[...] nas quais a ação precede a tomada de consciência descritiva e a compreensão [...]" (Piaget, 1978, p. 86) e, na medida em que as ideias foram sendo reconstruídas e aprimoradas, ou seja, na medida em que suas ações foram ficando mais complexas, estas ações comportaram conceituações. Estas conceituações ultrapassaram o nível do saber fazer e passaram a guiar as ações dos sujeitos (Piaget, 1978).

\section{Avaliação dos sujeitos sobre a arquitetura pedagógica Debate de Teses}

Na entrevista final, realizada no término do curso, os sujeitos avaliaram seu aprendizado com o suporte das arquiteturas. Em relação ao aprendizado oportunizado pelo Debate de Teses, sete sujeitos deram nota superior a 7. Os sujeitos destacaram que a maior contribuição da atividade foi comparar o seu posicionamento inicial e o final, verificando seus conhecimentos prévios e sua evolução no decorrer da atividade.

[...] Foi mais realmente a comparação do que eu me posicionei antes, no início, e no final. [...] (Sujeito E - Entrevista Final)

Também foi comentado por um dos sujeitos que é muito válido o processo de aprendizado e de debate com outras pessoas, principalmente quando não se tem uma compreensão sobre um determinado assunto.

[...] Sempre é válido tu aprender e discutir, debater com outras pessoas e aprender, porque se tu não sabes aquela afirmação... Então sempre é válido. (Sujeito D Entrevista Final)

A arquitetura também oportunizou um espaço de reflexão e experimentação de estratégias de feedback e contra-argumentação, aonde os sujeitos puderam refletir 
sobre todo o processo desde suas certezas provisórias até alcançar um patamar superior de conhecimento.

[...] Tudo é planejamento. Isso te ajuda a pensar e organizar melhor as coisas. Tu vê que não dá para fazer de qualquer jeito, tem que seguir uma linha de raciocínio, tem que organizar tudo bem direitinho, até para você ficar mais seguro, para ver que está no caminho certo, mais ou menos encaminhado. (Sujeito H - Entrevista Final)

Conforme relatou o sujeito $\mathrm{H}$, que deu nota nove para o aprendizado no Debate de Teses, a atividade o fez pensar e organizar melhor suas ideias. Dessa forma, ele pode ter certeza que está desenvolvendo o seu projeto da melhor forma possível.

\section{Avaliação dos sujeitos sobre a arquitetura pedagógica Desafio- Problema}

Todos os sujeitos deram nota superior a 8 para a estrutura do ambiente DesafioProblema. O fato de a arquitetura ter sido desenvolvida no Moodle, que foi o ambiente virtual de aprendizagem utilizado para o curso, facilitou o entendimento e o uso das ferramentas. Como alguns sujeitos comentaram na entrevista final que preferem realizar debates em grupo presencialmente, e que também estavam sem tempo para debates online, a única etapa da atividade que não foi tão bem avaliada foi o debate em grupo, no fórum. O sujeito $\mathrm{D}$ afirmou que só não deu dez para a estrutura da atividade porque o debate do seu grupo no fórum não foi construtivo. As demais etapas foram ótimas, pois oportunizaram ao sujeito D pensar como se fossem os empreendedores dos desafios.

Eu acho que eu dou 8 ou 9. Só por causa da questão do fórum, que atrapalhou, que não fluiu. Porque o resto foi bem legal: a gente assistiu os vídeos falando sobre os problemas e depois a gente pensou como eles. Foi muito bom. E depois trocar entre o nosso grupo, fazer essa troca de ideias. Acho que foi bem válido. E depois o aprendizado que a gente leva. [...] (Sujeito D - Entrevista Final)

O sujeito B comentou que a atividade o fez pensar na sua ideia de negócio e em desafios que irá enfrentar, que no seu caso era como alcançar seu público-alvo. Ele pode perceber o que não deu certo na empresa que apresentou o desafio e o que ele poderá mudar no seu negócio.

Olha, pra mim eu acho que 1o, porque contribuiu muito. Para pensar justamente isso que estava falando, de pensar nos problemas, de tentar solucionar, de pensar em vários caminhos onde eu possa percorrer e tentar achar uma solução para o problema. (Sujeito D - Entrevista Final) 
Lidar com situações vivenciadas por outros empreendedores oportunizou aos sujeitos um olhar mais crítico para as suas ideias de negócio e, consequentemente, para o seu potencial empreendedor. E esse potencial foi fortalecido no momento que os sujeitos conseguiram visualizar situações futuras que poderão ocorrer nos seus negócios e qual o melhor caminho que eles poderão seguir para transformar esses desafios em oportunidades.

\section{CONSIDERAÇÕES FINAIS}

Esta pesquisa teve como questão norteadora analisar como ocorreu o processo de construção de conhecimento sobre planejamento de negócios, dos alunosempreendedores do curso de extensão XIV Maratona de Empreendedorismo do UFRGS, a partir do uso das arquiteturas pedagógicas Debate de Teses e DesafioProblema: de empreendedor para empreendedor. Todo o percurso desta pesquisa desenvolveu-se na perspectiva de oferecer contribuições para a EAD e para a educação empreendedora, através do desenvolvimento e implementação de arquiteturas pedagógicas.

Respondendo ao problema desta pesquisa, a construção de conhecimento dos alunos-empreendedores sobre o tema planejamento de negócios ocorreu através de um processo de conceituação acerca de conceitos abordados nas arquiteturas pedagógicas Debate de Teses e Desafio-Problema, entre eles plano de negócios, modelo de negócios, mercado e planejamento financeiro.

A partir dos quatro níveis relacionados às duas categorias consideradas para a análise, todos os sujeitos alcançaram, no final do curso, um nível superior de compreensão em relação ao início do curso. O processo de conceituação - que iniciou numa compreensão inicial, evoluindo para uma compreensão conceitual parcial, depois alcançando uma compreensão contextualizada e, em alguns casos, uma compreensão antecipada - teve influência de alguns fatores. Os fatores foram: (i) conceituação e/ou reconstrução das certezas provisórias sobre conceitos relacionados ao planejamento de negócios; (ii) metarreflexão; (iii) contato e entendimento de desafios/problemas enfrentados pelos empreendedores e (iv) trabalho colaborativo.

Como este estudo foi realizado em um curso que ofereceu outras atividades, além das duas arquiteturas pedagógicas analisadas, não é possível concluir que apenas as arquiteturas pedagógicas influenciaram positivamente na conceituação do planejamento de negócios dos alunos-empreendedores. Em estudos posteriores, sugere-se realizar uma pesquisa num curso totalmente online e baseado na ideia de arquiteturas pedagógicas, podendo-se utilizar as mesmas arquiteturas pedagógicas adotadas nesta pesquisa.

Quanto à relevância das arquiteturas pedagógicas para a educação empreendedora, em especial para a Maratona de Empreendedorismo do UFRGS, reitera-se a importância de que elas sejam planejadas ou desenvolvidas com vista a aperfeiçoar algumas das competências exigidas pela sociedade contemporânea, 
sendo elas: autonomia, criatividade, trabalho em equipe, tomada de decisões, visualização de oportunidade em situações de fracasso, capacidade de aprender com situações novas e complexas, etc. Percebe-se, pelos resultados apresentados nesta pesquisa, que, em ambas as arquiteturas pedagógicas - Debate de Teses e DesafioProblema - essas competências puderam ser aprimoradas pelos sujeitos. Além do mais, as arquiteturas pedagógicas suscitaram reflexões e oportunizaram a tomada de consciência das ações desempenhadas pelos sujeitos, alcançando novos patamares de conceituação de planejamento das suas ideias de negócios. Nesses patamares já não é mais necessário agir para compreender a partir dos erros, pois os sujeitos podem antecipar possíveis erros, com a conceituação passando a direcionar as ações.

\section{NOTAS}

1. A SEDETEC promove a interação da Instituição com a sociedade, por meio do estímulo e apoio às atividades de desenvolvimento tecnológico e inovação.

2. Mais informações sobre a Maratona de Empreendedorismo da UFRGS podem ser acessadas através do link www.ufrgs.br/empreendedorismo

3. Esquema é o significado que o sujeito coloca no objeto através da ação, sendo visto como o motor do conhecimento. São os mecanismos de interação com o mundo, tendo como exemplo o ato de sugar, pegar, agarrar, etc.

4. O plano de negócios é uma ferramenta que possibilita um conhecimento aprofundado acerca da ideia do negócio, auxiliando o empreendedor a conhecer eantever os obstáculos enfrentados ao iniciar um negócio. No curso XIV Maratona de Empreendedorismo os alunos elaboraram o plano de negócios de suas ideias de negócio, sendo que os 10 melhores projetos apresentaram suas ideias para uma comissão avaliadora.

5. O ambiente Debate de Teses foi desenvolvido pela Universidade Federal do Espírito Santo (UFES) em parceria com a UFRGS. A equipe responsável foi o prof. Crediné Silva de Menezes e Ramon R. M. Vieira Junior, ambos da UFES, e a profa. Rosane Aragón, da UFRGS. A arquitetura está disponível através do link http://lied.inf.ufes. br/acesso/debateteses/dt/

\section{REFERÊNCIAS BIBLIOGRÁFICAS}

Becker, F. (1999). O sujeito do conhecimento: contribuições da epistemologia genética. Educação \& Realidade, Porto Alegre, 7389.

Becker, F. (2012). Educação e construção do conhecimento. 2. ed. Porto Alegre: Artmed.

Behar, P. A. (2009). Modelos pedagógicos em educação a distância. Porto Alegre: Artmed.
Belloni, M. L. (2008). Educação a distância. 5ta. ed. São Paulo: Autores Associados.

Coll, C., e Monereo, C. (2010). Psicologia da Educação Virtual: Aprender e ensinar com as tecnologias da informação e da comunicação. Porto Alegre: Artmed.

Dolabela, F. (2003). Pedagogia empreendedora. São Paulo: Ed. de Cultura. 
Freire, P. (1996). Pedagogia da autonomia: saberes necessários à prática educativa. São Paulo: Paz e Terra.

Flick, U. (2011). Desenho da pesquisa qualitativa. Porto Alegre: Artmed.

Lage, M. C. (2011). Utilização do software NVivo em uma pesquisa qualitativa: uma experiência em EaD. ETD - Educação Temática Digital, 12, 98-226. Campinas.

Lopes, R. M. A. (Org.). (2010). Educação empreendedora: conceitos, modelos $e$ práticas. Rio de Janeiro: Elsevier.

Ludke, M., e André, M. (1986). Pesquisa em educação: abordagens qualitativas. São Paulo: Editora Pedagógica e Universitária.

Michels, A. B. (2014). Do fazer ao compreender no contexto da educação a distância: uso de arquiteturas pedagógicas no processo de empreender. (Dissertação Mestrado), Universidade Federal do Rio Grande do Sul, Faculdade de Educação, Programa de Pós-Graduação em Educação, Porto Alegre.

Moore, M., e Kearsley, G. (2007). Educação a distância: uma visão integrada. Thomson.

Neck, H. M., Greene, P. G., e Brush, C. G. (2014). Teaching entrepreneurship: $a$ practice based-approach. Edward Elgar.

Nevado, R. A., Carvalho, M. J., e Menezes, C. S. (2007). Arquiteturas pedagógicas para educação a distância. In R. A. Nevado, M. J. Carvalho, e C. S. Menezes (Org.), Aprendizagem em rede na educação a distância: estudos e recursos para formação de professores. Porto Alegre: Ricardo Lenz.

Nevado, R. A., Menezes, C. S., e Vieira Jr, R. R. M. (2011). Debate de Teses: uma arquitetura pedagógica. Anais do XXII SBIE - XVII WIE. Aracaju.

Nevado, R. A., Dalpiaz, M. M., e Menezes, C. S. (2009). Arquitetura Pedagógica para Construção Colaborativa de Conceituacõoes. Recuperado de: http:/ www.lbd.dcc.ufmg.br/colecoes wie/2009/015.pdf

Piaget, J. (1974). A tomada de consciência. São Paulo: Melhoramentos.

Piaget, J. (1978). Fazer e compreender. São Paulo: Melhoramentos.

Piaget, J. (2011). Criatividade. In Vasconcellos, M. S. (Org.), Criatividade: Psicologia, Educação e Conhecimento do Novo. (11-20). São Paulo: Moderna.

Piaget, J. (2007). Epistemologia genética. 3ra. ed. São Paulo: Martins Fontes.

Piaget, J. (2010). Psicologia e pedagogia. 10ma. ed. Rio de Janeiro: Forense Universitária.

Pozo, J. I. (2002). Aprendizes e mestres: a nova cultura da aprendizagem. Porto Alegre: Artmed.

Souza, E. C. L., e Guimarães, T. A. (Org). (2005). Empreendedorismo além do plano de negócios. São Paulo: Atlas.

Yin, R. K. (2010). Estudo de caso. 4ta. ed. Porto Alegre: Bookman.

\section{PERFIL ACADÊMICO E PROFISSIONAL DAS AUTORAS}

Ana Beatriz Michels. Mestre em Educação, na linha de pesquisa de Educação a Distância, pela Universidade Federal do Rio Grande do Sul (UFRGS). Pósgraduada em Educação a Distância pelo Sistema Educacional EADCON. Graduada em Matemática Licenciatura pela Universidade Federal de Santa Catarina (UFSC). Coordenadora Pedagógica do Programa de Empreendedorismo da Secretaria de Desenvolvimento Tecnológico (SEDETEC) da UFRGS. Tem experiência na área de Educação, com ênfase em Tecnologia Educacional e Educação Empreendedora. E-mail: ana.michels@ufrgs.br 


\section{ENDEREÇO DO AUTOR}

Universidade Federal do Rio Grande do Sul (UFRGS)

Secretaria de Desenvolvimento Tecnológico (SEDETEC)

Praça Argentina, s/n, Prédio 11102

Campus Centro - UFRGS

90040-020, Porto Alegre, RS (Brasil)

Rosane Aragón. Doutora em Informática na Educação, mestre em Educação e graduada em Psicologia pela Universidade Federal do Rio Grande do Sul (UFRGS). Pós-doutorado pela Universidade Federal do Espírito Santo. Professora Associada da Faculdade de Educação da UFRGS e docente no Programa de Pós-Graduação em Educação (PPGEDU/UFRGS), Coordenadora do Curso de Pedagogia na modalidade a distância (PEAD) da UFRGS. Desenvolve pesquisas na área de Educação, com ênfase em Aprendizagem em Ambientes Digitais.

E-mail: rosane.aragon@ufrgs.br

\section{ENDEREÇO DO AUTOR}

Universidade Federal do Rio Grande do Sul (UFRGS)

Faculdade de Educação, Departamento de Estudos Básicos

Rua Paulo Gama, s/n, Prédio 12201

90046-900, Porto Alegre, RS (Brasil)

Fecha de recepción del artículo: 03/06/2015

Fecha de aceptación del artículo: 16/07/2015

\section{Como citar este artigo:}

Michels, A. B., y Aragón, R. (2016). Arquiteturas pedagógicas no processo de empreender: do fazer ao compreender no contexto da educação a distância. RIED. Revista Iberoamericana de Educación a Distancia, 19(2), pp. 263-281. doi: http:// dx.doi.org/10.5944/ried.19.2.14738 